\title{
A technique to artificially inseminate leafcutter ants
}

den Boer, Susanne; Boomsma, J. J.; Baer, B.

Published in:

Insectes Sociaux

DOI:

$10.1007 / \mathrm{s} 00040-012-0273-3$

Publication date:

2013

Document version

Early version, also known as pre-print

Citation for published version (APA):

den Boer, S., Boomsma, J. J., \& Baer, B. (2013). A technique to artificially inseminate leafcutter ants. Insectes Sociaux, 60, 111-118. https://doi.org/10.1007/s00040-012-0273-3 


\title{
A technique to artificially inseminate leafcutter ants
}

\author{
S. P. A. den Boer $\cdot$ J. J. Boomsma $\cdot$ B. Baer
}

Received: 12 September 2012/Revised: 31 October 2012/ Accepted: 21 November 2012/Published online: 7 December 2012

(C) International Union for the Study of Social Insects (IUSSI) 2012

\begin{abstract}
Artificial insemination (AI), the instrumental transfer of semen from the male to female reproductive organs, offers excellent opportunities to study mating system adaptations as it allows paternity to be experimentally manipulated. AI techniques have been developed for many animals, but rarely for ants, where they would be particularly useful as most species do not mate under controlled lab conditions. Here, we describe an AI technique for Atta leafcutter ants involving (1) the collection of ejaculates via induction of natural ejaculation, (2) storage in glass capillaries, and (3) transfer to queens using a modified AI equip ment as used for honeybees. Queens were fixed and anesthetized in a queen holder, after which the sting chamber was opened with two steel hooks, the tip of the semen-containing glass capillary was inserted into the bursa copulatrix and the semen slowly expelled. Sperm was successfully stored in the spermatheca of queens, and some queens produced a small colony as a result. We could furthermore confirm the earlier observations that Atta semen is directly transferred to the spermatheca rather than to the bursa copulatrix as in most
\end{abstract}

S. P. A. den Boer $(\bowtie)$ · J. J. Boomsma

Department of Biology, Centre for Social Evolution,

University of Copenhagen, Universitetsparken 15, 2100

Copenhagen, Denmark

e-mail: spadenboer@bio.ku.dk

S. P. A. den Boer · B. Baer

Centre for Integrative Bee Research, ARC CoE in Plant Energy

Biology, MCS Building M316, The University of Western

Australia, Crawley 6009, Australia

S. P. A. den Boer - B. Baer

Centre for Evolutionary Biology, School of Animal

Biology (MO92), The University of Western Australia,

Crawley 6009, Australia other eusocial insects. The technique that we present here can offer novel opportunities to study mating events such as sperm transfer, sperm competition, and cryptic female choice in ants. At present, the number of queens that produce colonies after AI remains low. However, this number will likely increase, as our results indicate that rearing conditions after AI influence colony founding success of artificially inseminated Atta queens.

Keywords Ejaculate $\cdot$ Mating biology $\cdot$ Social insects · Spermatheca $\cdot$ Sperm $\cdot$ Seminal fluid

\section{Introduction}

Artificial insemination (AI) is a technique where semen is collected from a male and transferred to the female's sexual tract using specifically developed instrumentation with the aim to obtain fertilized eggs or live-born offspring of controlled paternity. Artificial insemination is available for a wide range of species including humans (Chen and Wallach, 1994) and is frequently used for breeding domesticated animals such as cats (Axner, 2008), sheep (Evans and Maxwell, 1987), cattle, pigs, goats, rabbits, poultry, dogs, horses, and ostriches (see review by Foote, 2002), as well as for species requiring conservation breeding programs such as elephants, feline cats (Roth et al., 1997; Wildt and Roth, 1997), gazelles (Holt et al., 1996), pandas (Chen et al., 1994), and dolphins (Katsumata, 2010). AI techniques are also available for commercially valuable crustaceans such as the tiger prawn (Benzie et al., 1995) and the lobster (Aiken et al., 1984) and for insects such as honeybees (Mackensen and Roberts, 1948; Ruttner, 1975), the silkworm Bombyx mori (Takemura et al., 1996), bumblebees (Baer and Schmid-Hempel, 2000), and the bedbug Cimex 
lectularius (Davis, 1964). However, only a single paper describing the manual transfer of semen from males to queens has been published for ants (the fire ant Solenopsis invicta; Ball et al., 1983); to our knowledge, this study has never been elaborated further.

The development of an AI technique will ultimately allow to breed offspring with specifically desired genetic traits (Baer and Schmid-Hempel, 1999) and to experimentally study the mating biology of eusocial insects, where natural matings can often not be observed or manipulated in the lab. Artificial insemination bypasses pre-copulatory mate choice and thus also facilitates better focused studies of post-copulatory sexual selection (Baer et al., 2001) and the clarification of evolutionary relevant variables such as optimal ejaculate size, speed of ejaculate transfer, and sperm competition. Here, we describe an AI method for the leafcutter ant Atta colombica that offers various opportunities to study details of the mating biology of this species. Atta leafcutter ants are very suitable model organisms for AI because males and queens have large body sizes which facilitate the collection of substantial volumes of semen from males and the manipulation of queens during insemination. In addition, the sequence of events during natural copulation is reasonably well known: The reproductive organs of males consist of two accessory testes which store the mature spermatozoa (Baer and Boomsma, 2006; Baer and Boomsma, 2004) previously produced in the attached testes which have degenerated by the time males are sexually mature (Hölldobler and Bartz, 1985). The accessory testes are each accompanied by an accessory gland that provides a large part of the seminal fluid of ejaculates where it is vital for sperm viability (den Boer et al., 2008; den Boer et al., 2010; Stürup et al., 2011). The accessory testes and accessory glands open into the ejaculatory duct through which a mixture of sperm and seminal fluid is forcefully expelled upon ejaculation to reach the queen sexual tract via the endophallus. In contrast to most other insect species, semen is thus directly transferred to the queen's sperm storage organ (spermatheca, Fig. 1) rather than to the bursa copulatrix (Baer and Boomsma, 2006).

We used this information on ejaculate production, composition, and mode of transfer to develop a method which would reflect the processes occurring during natural copulations as precisely as possible. Our objective with the present communication is to share this methodology with researchers working on other ant species, as the technique may well be more widely applicable after some modifications. We also performed an experiment to validate our technique by measuring the effect of $\mathrm{AI}$ on queen lifespan and colony foundation success. Finally, we show that factors other than the actual insemination of ants can have a significant effect on AI success and need to be considered;

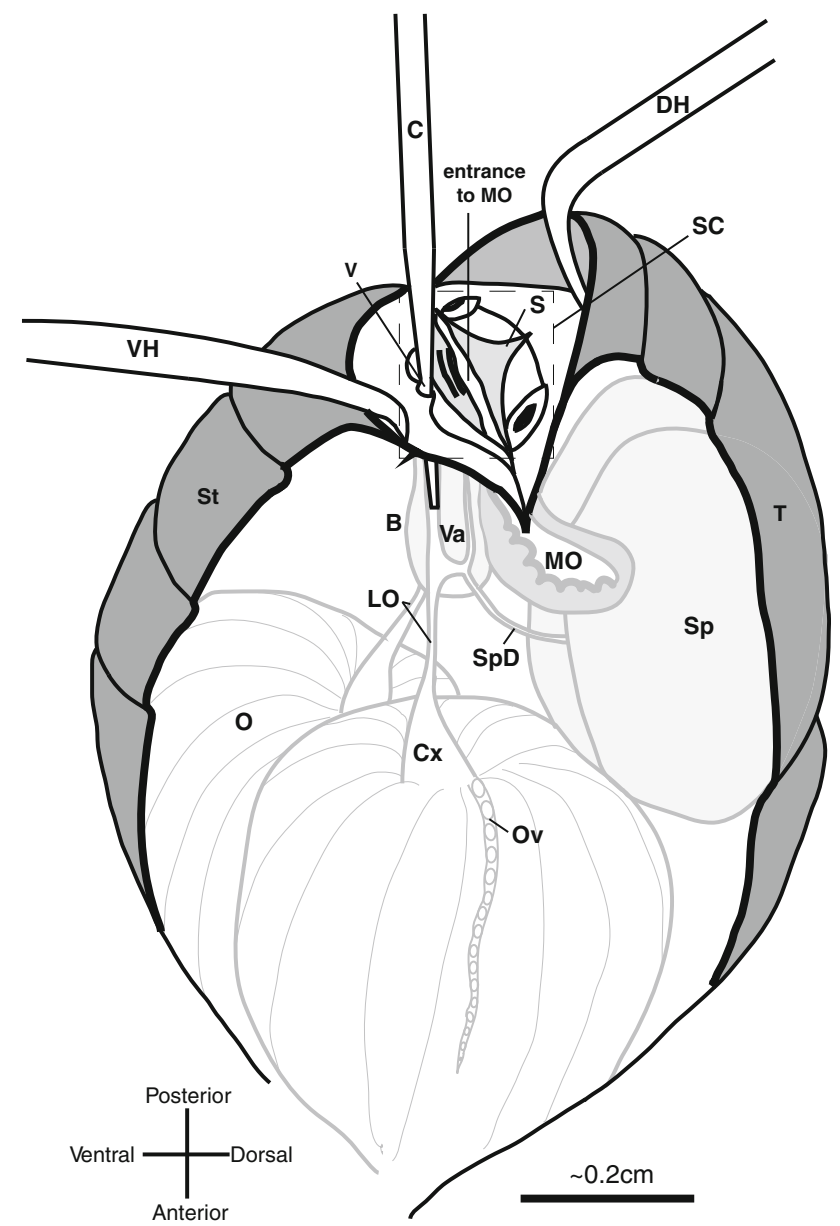

Fig. 1 A schematic representation of the abdomen of an Atta colombica queen during artificial insemination. A large part of the sternites and tergites have been removed from view, exposing the internal reproductive organs of the queen. The glass capillary can be seen inserted via the vagina into the bursa copulatrix. This capillary will allow semen to be transferred to the bilobular spermatheca via the spermathecal duct. In this view, the "mussel organ" organ, with its sclerotized ridges to which male genitalia attach during natural matings, is also visible. The ovaries are shown, and a single ovariole with eggs has been detailed. Ovaries as are shown here represent those of a mature Atta queen, virgin queens typically have much smaller ovaries at the time of insemination. $B$ bursa copulatrix, $C$ capillary, $C x$ calyx, $D H$ dorsal hook, $L O$ lateral oviduct, $M O$ mussel organ, $O$ ovary, $O v$ ovariole, $S$ sting (rudimentary), $S C$ sting chamber, $S p$ spermatheca, $S p D$ spermathecal duct, $S t$ sternite, $T$ tergites, $V$ vagina, $V a$ valve within the bursa copulatrix, $V H$ ventral hook

we demonstrate that the way in which inseminated queens are kept after AI significantly affects their lifespan.

\section{Methods}

All males and gynes used to develop the AI technique were randomly selected from ten different mature A. colombica colonies in Gamboa, Republic of Panama, in May 2009 and 
2010, all located within a 5-km radius of each other. The age of males and queens could not be determined, but we could confirm sexual maturity of males by dissecting a subset of individuals and verifying the complete degeneration of the testes and the presence of sperm in the accessory testes (Hölldobler and Bartz, 1985).

\section{Semen collection}

The first step in the AI process is collecting semen from males in a glass capillary attached to a syringe. We used a Schley syringe (Schley, Germany) and glass capillaries of $80 \mathrm{~mm}$ in length, $1.5 \mathrm{~mm}$ in diameter and with tips of $0.3 \mathrm{~mm}$ diameter.

There are three different methods to sample semen. First, sperm can be collected directly from male accessory testes after anesthetization with $\mathrm{CO}_{2}$ to prevent ejaculation and dissection of their reproductive organs. Dissected accessory testes were washed twice in Hayes saline $(9.0 \mathrm{~g} / \mathrm{l} \mathrm{NaCl}$, $0.2 \mathrm{~g} / \mathrm{l} \mathrm{CaCl}, 0.2 \mathrm{~g} / \mathrm{l} \mathrm{KCl}, 0.1 \mathrm{~g} / \mathrm{NaHCO}_{3}$ ) to reduce hemolymph contamination. A small hole was then pierced in the accessory testes with an injection needle and the outflowing sperm collected using a glass capillary. This method allows the collection of large undiluted volumes of sperm, but might differ from natural ejaculates as it does not contain the seminal fluid components which are secreted by the accessory glands.

Second, we collected whole ejaculates (sperm and seminal fluid) by a technique similar to that used for ejaculate collection in honeybees (Schley, 1987). To do so, the abdomen of a male was held between thumb and index finger and a small amount of pressure applied by gently squeezing the abdomen from the anterior to the posterior end. This method results in the appearance of an ejaculate (a mix of seminal fluid, sperm, and a small mating plug) at the tip of the endophallus, where it can be collected with a capillary. We tried to avoid collecting the small white mating plug as it can easily block the capillary.

Third, we found that decapitating mature males or surgically separating the abdomen and thorax can also stimulate ejaculation, allowing the collection of ejaculates from the tip of the endophallus as described above.

When collecting ejaculates, exposure of semen to air was minimized as this quickly dries out samples and clogs the tips of capillaries. At the end of each semen collection, we therefore cleaned the tips of glass capillaries by briefly flushing them with a small amount of Hayes saline. When keeping semen in capillaries for longer (for example, between the collection of semen samples of subsequent males, which was never longer than a few minutes). we sealed the tips with small amounts of Hayes saline. For the trials reported below, we never left semen inside the capillary for more than $20 \mathrm{~min}$ before AI.
Transfer of semen to the queen

For the transfer of semen to queens, we used commercially available insemination equipment for honeybees (Schley, Germany), which consists of a heavy base that supports a queen holder and queen hooks, as well as a syringe holder that is attached to a micromanipulator (Schley, Germany; see a similar setup in Baer and Schmid-Hempel, 2000; Fig. 2). Queens were anaesthetized with $\mathrm{CO}_{2}$ for up to 2 min before placing them in the queen holder. We used $\mathrm{CO}_{2}$ because we found that queens that are not sedated move around inside the queen holder resulting in their reproductive tissues being more likely to be damaged when inserting a capillary (visible as melanisation of the reproductive tract a day after AI), which could lead to early queen death.

Because Atta queens are much larger than honeybee queens, we designed a larger queen holding device by modifying $1.5-\mathrm{ml}$ eppendorf tubes, resulting in a holder of ca. $2 \mathrm{~cm}$ long and $1 \mathrm{~cm}$ wide. To open the queen's sting chamber (the chamber below the most posterior sternite and tergite, where a structure homologous to the functional sting of bees and ants can be seen, as well as where the entrance to the bursa copulatrix and mussel organ are located, see Fig. 1), we either used the ventral and dorsal hooks used for honeybee queen insemination (Schley, Germany) or we made our own hooks by bending the tips of injection needles after polishing them with a wet stone to make them blunt to avoid damaging queen tissues. The queen hooks were placed over the last tergite and sternite to allow opening of the sting chamber by gently pulling the hooks apart (Figs. 1,2).
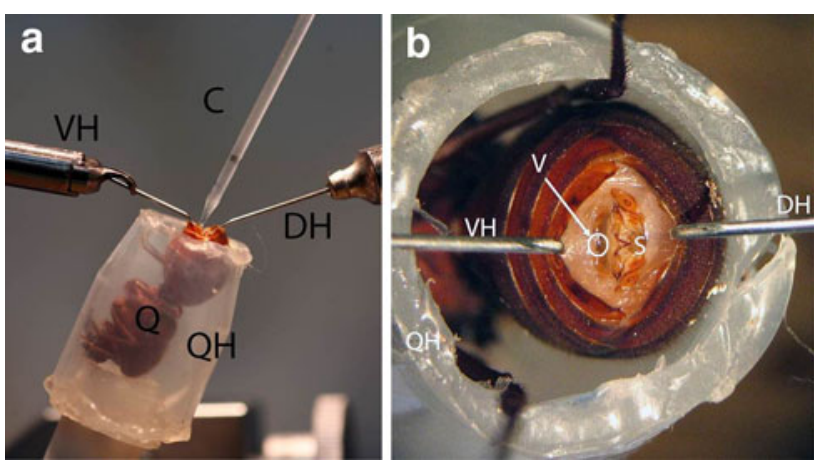

Fig. 2 a Lateral view of an Atta colombica queen $(Q)$ in the queen holder $(Q H)$ during artificial insemination. Dorsal $(D H)$ and ventral $(V H)$ steel hooks were used to gain access to the female sexual tract. The semen-containing capillary has been inserted into the vagina and the sperm has already been injected. No back flowing sperm residuals can be seen where the glass capillary entered, indicating that all sperm have been transferred. b Posterior view of the opening of an A. colombica queen's sexual tract after immobilizing her in a queen holder $(Q H)$. The opening of the sexual tract ( $V$ vagina), where the sperm containing glass capillary is inserted is located dorsally of the sting apparatus $(S)$ and marked with a white circle 
We found the opening to the queen's bursa copulatrix to be located ventrally to the so-called "mussel-organ" (the female organ where the sclerotized parts of the male endophallus attach, see Baer and Boomsma, 2006; Figs. 1, $2 b)$. The glass capillary was carefully introduced, not more than $2 \mathrm{~mm}$ into the small opening so that sperm could slowly be released (Figs. 1, 2a). Correct placement of the capillary was confirmed when no sperm could be seen leaking back out of the queen's sexual tract.

\section{Optimizing insemination procedures}

We initially tested our methods by inseminating 20 virgin queens with either semen or with black ink and we dissected these queens shortly after AI to determine whether the semen or ink had become successfully stored in the spermatheca. We then artificially inseminated another 135 queens with semen ejaculated by males, collected by applying pressure to the abdomen as described above. To determine the volume of ejaculate needed to inseminate queens, we quantified the average sperm concentration in semen after collecting ten mature males, sampling $5 \mu \mathrm{l}$ of ejaculate per male, and diluting these samples in $995 \mu 1$ Hayes saline. After $25 \mu \mathrm{l}$ of this solution was diluted further in $975 \mu \mathrm{l}$ Hayes saline, two $1 \mu \mathrm{l}$ subsamples were placed on a microscope slide and $2 \mu \mathrm{l}$ of a 4',6-diamino-2phenylindole (DAPI) working solution, i.e., $2 \mu$ DAPI stock solution ( $2 \mathrm{mg}$ DAPI in $1 \mathrm{ml}$ DMSO) in $1 \mathrm{ml}$ Hayes saline, was added to each sample. Slides were examined using a fluorescence microscope (Olympus CX41, EXFO $X$-Cite 120) and all the sperm cells in each sample counted. Original sperm numbers were then calculated by multiplying with the dilution factor and taking the average over two droplets. We found that male ejaculates contained $6.69 \times 10^{6} \pm 2.84 \times 10^{5}($ mean $\pm \mathrm{SEM})$ sperm cells $/ \mu \mathrm{l}$. As queens store between 100 and 244 million sperm cells in their spermatheca after mating (Fjerdingstad and Boomsma, 1997, 1998; Baer et al., 2006), we inferred that 14.9-36.5 $\mu \mathrm{l}$ of ejaculate was required to fully inseminate a virgin queen. We inseminated queens with a range of volumes around the lower bound of this estimate, i.e., 4-20 $\mu \mathrm{l}$ (mean $\pm \mathrm{SEM} ; 13.39 \pm 0.45 \mu \mathrm{l}$ ), as our objective was to make queens successfully store sperm and use it for the production of worker offspring, not to offer them enough sperm for a life-time of 10 years or more (den Boer et al., 2009a).

The number of males we used to inseminate a single queen ranged from 1 to 12 , with a mean of $4.0 \pm 0.2$ (mean $\pm \mathrm{SEM}$ ), corresponding approximately to the average number of fathers found among worker offspring of naturally inseminated queens (2-7 males; Baer et al., 2006; Fjerdingstad et al., 1998; Evison and Hughes, 2011).
Queen rearing conditions after AI

After insemination, we placed queens in a small petridish with moist cotton and kept them in the dark at ca. $27{ }^{\circ} \mathrm{C}$ and $95 \% \mathrm{rH}$. For a subgroup of queens $(n=84)$, we varied rearing conditions to examine possible effects on queen survival and colony founding success. We housed 31 queens in petridishes filled with soil to allow queens to dig a burrow as they are known to do in the field after mating (Baer et al., 2006). Another 20 queens were housed with soil and a small fragment of fungus garden from their maternal colony. Finally, we also set up $33 \mathrm{AI}$ queens without soil, but with a piece of fungus garden and five small workers from their maternal colony. Fungus and workers were replaced every few days. Queens were checked daily so that we could record survival (days after $\mathrm{AI}$ ) and the appearance of eggs, larvae, and workers. Once queens successfully produced workers, we supplied all with a new small piece of fungus garden from the queen's maternal fungus garden and replaced it every couple of days for the first few weeks until we observed that the workers were able to maintain a healthy fungus garden themselves.

Statistical analyses of the data were carried out using IBM SPSS 20 for Windows. We analyzed the effect of rearing conditions on survival using a Kruskall Wallis test, followed by Mann-Whitney tests to assess lower-level differences using Bonferroni corrected $p$ values (0.0167 instead of 0.05) to prevent Type I errors due to multiple testing.

\section{Results}

When examining an initial sample of 20 queens which we inseminated with either sperm or ink, we found that sperm/ ink could almost exclusively be observed in the spermatheca and that no sperm or ink was detected in the ovaries or in the hemolymph. This is consistent with the location of semen in naturally inseminated queens shortly after mating (Baer and Boomsma, 2006). Only in 1 out of 20 queens, we found residual amounts of semen or ink in the bursa copulatrix, indicating that sperm is transferred directly to the spermatheca during copulation and that our technique thus emulated natural inseminations without noticeable damage to the queens' reproductive organs.

Eight $(5.9 \%)$ of the 135 AI queens (102 in 2009 and 33 in 2010) ended up laying eggs, and three of them (1.5\%) eventually produced a small colony with more than 20 workers. The lifespan of queens ranged from 1 to 252 days with a median lifespan of 6 days after AI (Fig. 3). Queens initiated egg laying between 3 and 14 days after AI with a median of 9.5 days. Of the queens that survived longer than 9 days, $21.6 \%$ ultimately laid eggs with $8.1 \%$ producing a colony with at least 20 workers. 


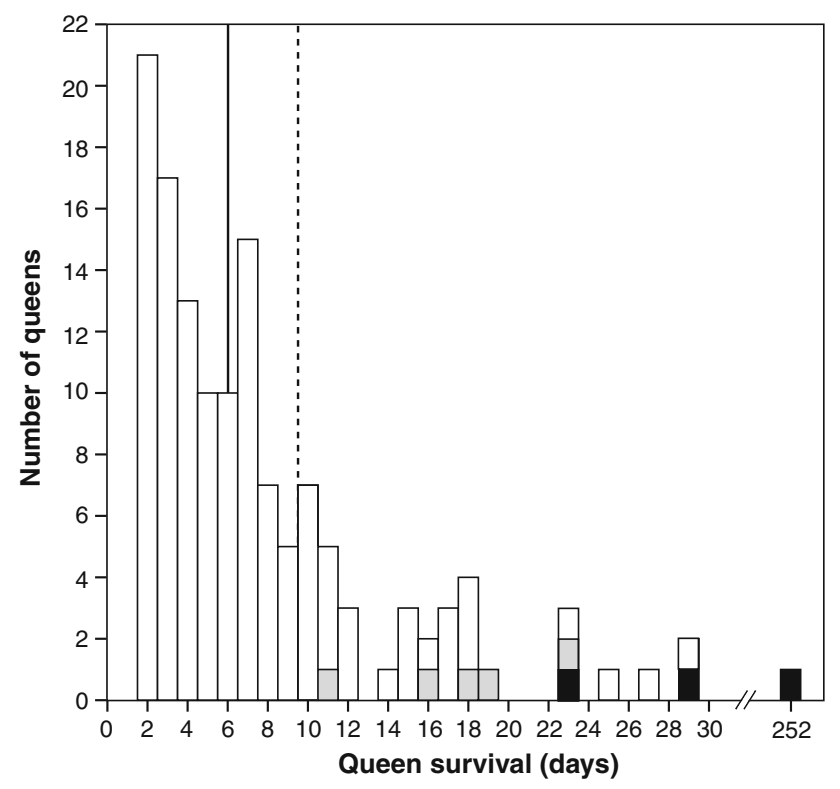

Fig. 3 Frequency distribution of queen survival in days after artificial insemination. White bars represent queens that did not produce any brood, gray bars represent queens that produced eggs only, and black bars represent queens that produced a small colony ( $>20$ workers). The solid vertical line indicates median queen survival and the dashed vertical line represents the median onset of egg laying

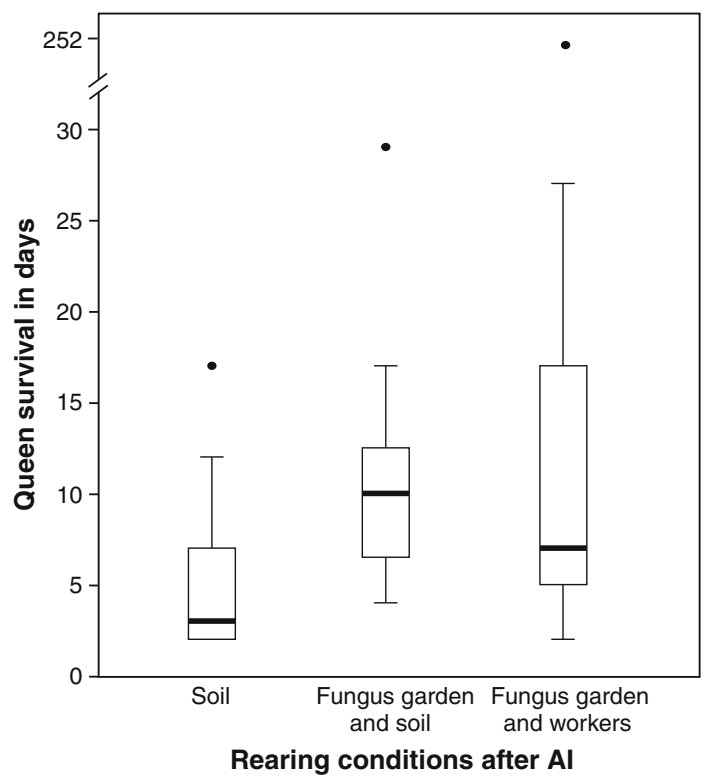

Fig. 4 The effect of rearing conditions after artificial insemination on queen survival and egg laying. Queens were either kept in a petridish with soil only $(n=31)$ or with a piece of fungus garden and soil $(n=20)$ or with a piece of fungus garden en workers $(n=33)$. Boxplots show median (thick horizontal line), upper and lower quartile (box), minimum and maximum values (whiskers) and outliers (dots)

We found a significant effect of rearing conditions on queen survival (Fig. 4, Kruskall Wallis, $H=18.452$, $p<0.001$ ). Queens set up in a petridish filled with soil only survived significantly shorter (median: 3 days) than those reared in a petridishes where we provided them with soil and fungus (median: 10 days, $U=105.5$, effect size $r=$ -0.56 ) or fungus and workers (median: 7 days, $U=273.5$, $r=-0.40$ ). There was no significant difference between the latter two rearing categories $(U=264, r=-0.17)$.

None of the queens that we provided with soil alone laid eggs, but egg laying was initiated when we provided queens with fungus and soil (5.3\%) or fungus and workers (13.8\%) (Fig. 4), but the difference between these alternatives was not significant [Pearson Chi-Square, $\chi^{2}(2)=$ $4.238, p=0.120]$.

\section{Discussion}

The AI technique that we adapted for Atta leafcutter ant queens is relatively easy to use and allows the insemination of large numbers of queens in short periods of time. The technique is feasible, as some queens initiated a colony and produced worker offspring. This implies that already with our present results, the technique is suitable for studying some aspects of the mating biology of Atta leafcutter ants with levels of detail (e.g., den Boer et al., 2008; den Boer et al., 2010) that have not been possible in other ants. For example, we have previously used parts of the technique described here to collect sperm samples from the accessory testes to study the effects of male accessory gland secretion (part of the seminal fluid component of ejaculates) on sperm viability (den Boer et al., 2008; den Boer et al., 2009b; den Boer et al., 2010) and its role in sperm competition (den Boer et al., 2010). In addition, we have used AI to harvest queen spermathecal secretions and examined their effect on sperm physiology, after inseminating queens with saline solution which was subsequently dissected out of the spermatheca (den Boer et al., 2010).

The applicability of AI as a technique to study mating biology has been documented for decades for honeybees and more recently also for bumblebees. In honeybees, AI has been used to study queen flight behavior, brain and ovary gene expression, queen mandibular gland chemical profiles, and worker-queen interactions in response to ejaculates being transferred to the spermatheca (Richard et al., 2007; Kocher et al., 2010). AI was also used to examine the sexual transmission of deformed wing virus (de Miranda and Fries, 2008; Yue et al., 2007) and the effect of semen quality on queen egg laying (Collins, 2004). In bumblebees, AI techniques have been useful tools to understand changes in female physiology after mating, as compounds in the male ejaculate could be shown to influence queen remating rates (Baer et al., 2001), sperm transfer (Duvoisin et al., 1999), and queen survival after hibernation (Baer et al., 2001; Duvoisin et al., 1999; Korner and 
Schmid-Hempel, 2003). The development of AI in ants can therefore facilitate similar studies on reproductive biology in this group of species.

At present, the number of queens that successfully established a colony with workers remains low (1.5\%), which appears to be partly due to a lack of knowledge about the optimal conditions required by queens after insemination. It is important to point out that in honeybees, where AI is now done routinely for breeding purposes of managed stock, the technique has been continuously improved over the last decades (Ruttner, 1975). It would thus seem natural that more work will be needed to improve success rates in Atta and other ants before routine breeding of colonies with known paternity and maternity will be possible.

We found that providing queens with small fragments of their maternal fungus garden and with workers from their maternal colony significantly increased the survival of queens after AI. We hypothesize that the presence of fungus garden material reduces stress levels and possibly buffers fluctuations in humidity, but that the opportunity to feed is less relevant because naturally inseminated queens found colonies claustrally and without eating for months while metabolizing their wing muscles and fat bodies (Weber, 1972). Worker grooming did not increase survival beyond what soil and fungus could induce, suggesting that the presence of workers per se is not a main factor either, which would be consistent with workers being absent during natural colony founding. However, adding some workers to maintain the fungus garden is likely to be prudent and to be preferred over adding soil which is likely to increase infection risks of queens and garden fragments.

Another potential problem, the quality of the male and queen individuals which we used for the AI experiments, is more difficult to control. We only used males of which the testes had degenerated so that all sperm was stored in the accessory testes, but these markers of sexual maturity (Hölldobler and Bartz, 1985) are likely to be incomplete. Ideally, one would like to sample males on the day that nuptial flights take place, but that would create minimal time to actually do AI experiments. Sampling earlier thus incurs the risk that the quality of sperm and/or seminal fluid is not optimal, which might affect the physiological interactions with female tissue in a negative manner. Ant males normally lose weight between hatching and leaving for their mating flight (Boomsma et al., 1995) so that a sample of males collected just before take-off would be useful to develop a species-specific reference curve of weight versus body size (e.g., head width or pronotum width) to facilitate screening earlier collected males for optimal sexual maturity.

While we were reasonably confident that the quality of the males that we used was not too far from optimal, this was less likely to be the case for the virgin queens that we inseminated. In general, Atta queens appear later in the most accessible fungus gardens (just below the surface) than males so they will have tended to be somewhat less mature when we collected them. The mass of virgin queens increases substantially after hatching, reaching an asymptote some days or weeks before environmental conditions allow a mating flight to take place (Boomsma et al., 1995) so also for gynes a reference curve plotting mass as a function of body size (e.g., pronotum weight) would be desirable for future work. However, gyne (and male) weights differ across years and colonies (Stürup et al., 2011; Fjerdingstad and Boomsma, 1997), and mating flights of A. colombica take place at night, with their onset hard to predict, so that we were unable to collect such reference curves when we did the AI work. Even if these data would have been available, we could only have used them in a post hoc manner.

Storing sperm has been shown to be costly in A. colombica (Baer et al., 2006), suggesting that optimal mass (relative to age and body size) of males and particularly queens is likely to matter for survival after mating so body size might also affect the likelihood that AI will lead to viable incipient colonies. In the related species Atta texana, larger founding queens have a higher survival before worker emergence than smaller queens (Mintzer, 1987). The same was found for the harvester ant Pogonomyrmex occidentalis (Wiernasz and Cole, 2003). Queen and male age is also important for AI success in the honeybee Apis mellifera, where decades of bee breeding have shown that more queens survive and successfully produce offspring when they are inseminated roughly 7-10 days after hatching (Cobey, 2007) and using the semen of males that are about 2-weeks old, when semen quality is highest (Locke and Peng, 1993). We obtained further indications of the importance of optimal starting material by scrutinizing the fire ant AI data by Ball et al. (1983). The percentage of fire ant queens producing pupae after AI was found to be higher (27\%) than in our study, but Ball et al. (1983) apparently only used queens that were engaging in flights just prior to AI so that optimal sexual maturity at that point was highly likely.

In conclusion, the technique to artificially inseminate leafcutter ant queens that we present here would seem adaptable for use in other ant species. Once the technique is further optimized so that queens can predictably produce colonies, AI can also be used to study within-colony dynamics, for example by varying the number of contributing fathers and thereby influencing relatedness between colony members. We identified and discussed some factors to increase AI success, such as rearing conditions after AI and queen and male quality parameters such as age, size, and potentially also genotype, but substantial further work will be needed to approach success rates known for honeybees and bumblebees. 
Acknowledgments We thank the Smithsonian Tropical Research Institute (STRI) in Panama for facilities and logistic support and the Autoridad Nacional de Ambiente (ANAM) for issuing collection permits. This work was supported by a Marie Curie International Outgoing Fellowship to SPAdB, a grant from the Danish National Research Foundation to JJB and several grants from the Australian Research Council to BB.

\section{References}

Aiken D.E., Waddy S.L., Moreland K. and Polar S.M. 1984. Electrically induced ejaculation and artificial insemination of the American lobster Homarus americanus. J. Crust. Biol. 4: 519527

Axner E. 2008. Updates on reproductive physiology, genital diseases and artificial insemination in the domestic cat. Reprod. Domest. Anim. 43: 144-149

Baer B., Armitage S.A.O. and Boomsma J.J. 2006. Sperm storage induces an immunity cost in ants. Nature 441: 872-875

Baer B. and Boomsma J. 2004. Male reproductive investment and queen mating-frequency in fungus-growing ants. Behav. Ecol. 15: $426-432$

Baer B. and Boomsma J.J. 2006. Mating biology of the leaf-cutting ants Atta colombica and A. cephalotes. J. Morphol. 267: $1165-1171$

Baer B., Morgan E.D. and Schmid-Hempel P. 2001. A nonspecific fatty acid within the bumblebee mating plug prevents females from remating. Proc. Natl Acad. Sci. U.S.A. 98: 3926-3928

Baer B. and Schmid-Hempel P. 1999. Experimental variation in polyandry affects parasite loads and fitness in a bumble-bee. Nature 397: 151-154

Baer B. and Schmid-Hempel P. 2000. The artificial insemination of bumblebee queens. Insect. Soc. 47: 183-187

Ball D.E., Mirenda J.T., Sorensen A.A. and Vinson S.B. 1983. Instrumental insemination of the fire ant, Solenopsis invicta. Entomol. Exp. Appl. 33: 195-202

Benzie J.A.H., Kenway M., Ballment E., Frusher S. and Trott L. 1995. Interspecific hybridization of the tiger prawns Penaeus monodon and Penaeus esculentus. Aquaculture 133: 103-111

Boomsma J.J., Keller L. and Nielsen M.G. 1995. A comparative analysis of sex-ratio investment parameters in ants. Funct. Ecol. 9: $743-753$

Chen M., Zhang G. and Mainka S.A. 1994. Semen evaluation of giant pandas (Ailuropoda melanoleuca) at the Wolong Reserve. Zoo Biol. 13: 83-86

Chen S.H. and Wallach E.E. 1994. Five decades of progress in management of the infertile couple. Fertil. Steril. 62: 665-685

Cobey S.W. 2007. Comparison studies of instrumentally inseminated and naturally mated honey bee queens and factors affecting their performance. Apidologie 38: 390-410

Collins A.M. 2004. Functional longevity of honey bee, Apis mellifera, queens inseminated with low viability semen. J. Apic. Res. 43: 167-171

Davis N.T. 1964. Studies of the reproductive physiology of Cimicidae (Hemiptera) II. Artificial insemination and the function of the seminal fluid. J. Insect Physiol. 11: 355-366

de Miranda J.R. and Fries I. 2008. Venereal and vertical transmission of deformed wing virus in honeybees (Apis mellifera L.). J. Invertebr. Pathol. 98: 184-189

den Boer S.P.A., Baer B. and Boomsma J.J. 2010. Seminal fluid mediates ejaculate competition in social insects. Science 327: 1506-1509 den Boer S.P.A., Baer B., Dreier S., Aron S., Nash D.R. and Boomsma J.J. 2009a. Prudent sperm use by leafcutter ant queens. Proc. R. Soc. Lond., B, Biol. Sci 276: 3945-3953

den Boer S.P.A., Boomsma J.J. and Baer B. 2008. Seminal fluid enhances sperm viability in the leafcutter ant Atta colombica. Behav. Ecol. Sociobiol. 62: 1843-1849

den Boer S.P.A., Boomsma J.J. and Baer B. 2009b. Honey bee males and queens use glandular secretions to enhance sperm viability before and after storage. J. Insect Physiol. 55: 538-543

Duvoisin N., Baer B. and Schmid-Hempel P. 1999. Sperm transfer and male competition in a bumblebee. Anim. Behav. 58: 743-749

Evans G. and Maxwell W.M.C. 1987. Salamons Artificial Insemination of Sheep and Goats. Butterworths, Sydney.

Evison S. and Hughes W. 2011. Genetic caste polymorphism and the evolution of polyandry in Atta leaf-cutting ants. Naturwissenschaften 98: 643-649

Fjerdingstad E.J. and Boomsma J.J. 1997. Variation in size and sperm content of sexuals in the leafcutter ant Atta colombica. Insect. Soc. 44: 209-218

Fjerdingstad E.J. and Boomsma J.J. 1998. Multiple mating increases the sperm stores of Atta colombica leafcutter ant queens. Behav. Ecol. Sociobiol. 42: 257-261

Fjerdingstad E.J., Boomsma J.J. and Thorén P. 1998. Multipe paternity in the leafcutter ant Atta colombica - a microsatellite DNA study. Heredity 80: 118-126

Foote R.H. 2002. The history of artificial insemination: Selected notes and notables. J. Anim. Sci. 80: 1-10.

Hölldobler B. and Bartz S.H. 1985. Sociobiology of reproduction in ants. In: Experimental Behavioral Ecology (Hölldobler B., Ed). G. Fischer Verlag, Stuttgart. pp 237-257

Holt W.V., Abaigar T. and Jabbour H.N. 1996. Oestrous synchronization, semen preservation and artificial insemination in the Mohor Gazelle (Gazella dama mhorr) for the establishment of a genome resource bank programme. Reprod. Fertil. Dev. 8: 12151222

Katsumata E. 2010. Study on reproduction of captive marine mammals. J. Reprod. Dev. 56: 1-8

Kocher S.D., Tarpy D.R. and Grozinger C.M. 2010. The effects of mating and instrumental insemination on queen honey bee flight behaviour and gene expression. Insect Mol. Biol. 19: 153-162

Korner P. and Schmid-Hempel P. 2003. Effects of sperm on female longevity in the bumblebee Bombus terrestris L. Proc. R. Soc. Lond. B, Biol. Sci 270: 227-229

Locke S. and Peng Y. 1993. The effects of drone age, semen storage and contamination on semen quality in the honey-bee (Apis mellifera). Physiol. Entomol. 18: 144-148

Mackensen O. and Roberts W.C. 1948. A Manual for the Artificial Insemination of Queen Bees. U.S. Dept. of Agriculture, Agricultural Research Administration, Bureau of Entomology and Plant Quarantine, $33 \mathrm{pp}$

Mintzer A. 1987. Primary polygyny in the ant Atta texana: Number and weight of females and colony foundation success in the laboratory. Insect. Soc. 34: 108-117

Richard F.J., Tarpy D.R. and Grozinger C.M. 2007. Effects of insemination quantity on honey bee queen physiology. Plos One 2: 9

Roth T.L., Armstrong D.L., Barrie M.T. and Wildt D.E. 1997. Seasonal effects on ovarian responsiveness to exogenous gonadotrophins and successful artificial insemination in the snow leopard (Uncia uncia). Reprod. Fertil. Dev. 9: 285-295

Ruttner F. 1975. Die instrumentelle Besamung der Bienenkönigin. Apimondia Publishing House, Bucharest.

Schley P. 1987. Einführung in die Technik der instrumentellen Besamung von Bienenköniginnen. Köhler Offset KG, Giessen. 
Stürup M., den Boer S.P.A., Nash D.R., Boomsma J.J. and Baer B. 2011. Variation in male body size and reproductive allocation in the leafcutter ant Atta colombica: estimating variance components and possible trade-offs. Insect. Soc. 58: 47-55

Takemura Y., Kanda T., Tamura T., Shinbo H. and Horie Y. 1996. Development of new method for artificial insemination of the silkworm, Bombyx mori. J. Seric. Sci. Jpn. 65: 456-463

Weber N.A. 1972. Gardening Ants, the Attines. The American Philosophical Society, Philadelphia.
Wiernasz D.C. and Cole B.J. 2003. Queen size mediates queen survival and colony fitness in harvester ants. Evolution 57: 2179-2183

Wildt D.E. and Roth T.L. 1997. Assisted reproduction for managing and conserving threatened felids. Int. Zoo Yb. 35: 164-172

Yue C., Schroder M., Gisder S. and Genersch E. 2007. Vertical transmission routes for deformed wing virus of honeybees (Apis mellifera). J. Gen. Virol. 88: 2329-2336 